1 Evidencing the impact of coaches' learning: Changes in coaching

2 knowledge and practice over time

$3 \quad$ Anna Stodter ${ }^{\mathrm{a}}$ and Christopher J. Cushion ${ }^{\mathrm{b}}$

$4{ }^{a}$ Cambridge Centre for Sport and Exercise Sciences, Anglia Ruskin University,

5 Cambridge, UK; ${ }^{b}$ School of Sport, Exercise and Health Sciences, Loughborough

6 University, Loughborough, $U K$

$7 \quad$ Corresponding author: Anna.Stodter@anglia.ac.uk

8

9

10

11

12

13

14

15

16

17

18

19

20 


\section{Evidencing the impact of coaches' learning: Changes in coaching \\ 22 knowledge and practice over time}

It is clear that sport coaches learn from multiple interconnected learning experiences, yet there is limited direct evidence to elucidate what is learned and how these combined experiences shape coaches' knowledge and day-to-day practice. This research aimed to investigate the impact of the learning of two groups of English youth soccer coaches over a period of a year and a half. Using the Coach Analysis and Intervention System (CAIS) and associated video-stimulated recall interviews, changes in the practice behaviours and knowledge use of coaches completing a formal coach education course, and equivalent coaches not undertaking formal education, were compared. Data indicated that the learning period had a different effect on coaches taking part in formal coach education versus those not in education. Changes in the use of knowledge about individual players and tactics were reflected in increased behaviours directed towards individuals, and an altered proportion of technical to tactically-related questioning, linked to coaches' participation in education. Overall, more change was evident in coaching knowledge than in practice behaviours, suggesting an absence of deep learning that bridged the knowledgepractice gap.

Keywords: Coach learning, coaching behaviours, knowledge development, coach education, impact evaluation

\section{Introduction}

There is an ongoing concern to outline optimal frameworks for formal coach development that bring learning "under greater critical control” (Eraut, 1994, p. 62). A consequence of this is a proliferation of prescriptions for coach education drawing on existing literature, which consists of surveys and retrospective opinion-based 
46 studies that describe and categorise the perceived development of coaches, isolating

47 particular learning sources or aspects of formal education programmes (e.g. Deek,

48 Werthner, Paquette \& Culver, 2013; Søvik, Tjomsland, Larsen, Samdal \& Wold,

49 2017; Stoszkowski \& Collins, 2015, inter-alia). These studies show that coaches value

50 learning through years of ongoing participation in practice as an athlete and coach

51 while also taking advantage of a variety of learning experiences ranging in formality

52 (Lara-Bercial \& Mallett, 2016). However, categorising sources of coaches' knowledge

53 and exploring the use of discrete learning practices are limited as coaches learn

54 different things from apparently similar situations (Stodter \& Cushion, 2017). Any

55 learning situation therefore can only be understood with reference to the blend that

56 constitutes the coach's wider learning and their continuously evolving biography or

57 network of knowledge, beliefs and attitudes (Trudel, Gilbert \& Werthner, 2010). The

58 existing literature gives limited insight into how learning impacts coaches and

59 coaching, meaning there is a lack of robust empirical evidence to ascertain what

60 coaches gain and use from different learning experiences over time.

This significant gap links to the challenges of measuring, evaluating and

62 promoting effective learning (Griffiths, Armour \& Cushion, 2016). Evaluation models

63 in education argue for levels of assessment above participants' reactions, to include

64 learning of knowledge, skills and perhaps attitudes, changes in the use of new

65 knowledge and skills, and outcomes of the programme (Coldwell \& Simkins, 2011).

66 Self-report data are limited, particularly in coaching where coaches show poor self-

67 awareness; perceptions of practice do not correlate with observed behaviour, or with

68 underpinning knowledge (Millar, Oldham \& Donovan, 2011; Partington \& Cushion,

69 2013). Therefore, looking beyond self-report measures is important, and evaluation of 
70 learning should focus on cognition and observable behaviour, not in isolation but

71 interacting in practice (cf. Cushion, Ford \& Williams, 2012).

Cognitive standpoints frame learning as "the process whereby knowledge is 73 acquired" or "is used in a new context or in new combinations" (Eraut, 2000, p.114).

74 One way to gauge coaches' learning is to look beyond acquisition, investigating

75 changes in the content of knowledge and how it is used over time. Stoszkowski and

76 Collins (2015) showed coaches desired information about pedagogy, and sport-

77 specific knowledge, but practitioners' justification for and application of knowledge

78 was absent, providing only retrospective perceptions of learning as knowledge 79 acquisition.

The integration of knowledge, theory and practice is a key area that is difficult

81 to develop (Nelson, Cushion \& Potrac, 2012). Gilbert and Côté (2013) claim that since

82 knowledge manifests in coaches' behaviours, naturalistic behaviour research should

83 be integral to our understanding of coaches' learning. Behavioural observations can

84 assess learning as behaviour change, a proxy for the knowledge coaches translate and

85 how it is implemented (Cope, Partington \& Harvey, 2017). Although behavioural

86 observation shows 'what coaches do' to be a mix of instruction, positive verbalisations

87 and periods of silence (cf. Cushion et al., 2012a), the coaching process is dynamic and

88 subject to myriad situational, contextual and social factors. In addition, with the

89 exception of Partington and colleagues' (2015) investigation of coaches' behaviour

90 change, the research provides a static picture of practice limited by observations over

91 a period of a few sessions (Cope et al., 2017). Little is known about how behaviours

92 evolve over time, or how they alter alongside coaches' supporting reasoning,

93 developing knowledge or learning. Single measure research designs without a baseline 
94 or comparison groups overlook the temporal nature of learning (Goodall et al., 2005),

95 therefore failing to evidence meaningful change.

Only a handful of small scale case-studies have used more rigorous

97 longitudinal, multi-dimensional comparisons related to coaching practice to explore

98 changes in knowledge or situated behaviour. Integrating participant observation, pre-

99 and post-course interviews, systematic observation and stimulated recall, Gilbert and

100 Trudel (1999) and Stodter and Cushion (2014) found minimal changes in coaches'

101 practice linked to periods of formal learning. Meanwhile, interventions involving

102 individual coaches in self-assessing their behaviours and setting associated goals have

103 resulted in modified behaviours and heightened self-awareness (DeMarco, Mancini \&

104 Wuest, 1997; Gallo \& De Marco, 2008). However, without comparison groups,

105 separating the impact of different types of learning situation from simultaneously

106 occurring experiences and moderating factors is problematic. The aim of this study

107 was to address these challenges by examining the impact of coaches' learning, through

108 the assessment of changes in the coaching knowledge and behaviours of groups of 109 coaches undertaking, and not undertaking formal education. Coaches' use of

110 knowledge was investigated alongside behaviours, providing another layer to inquiry

111 over time. The significance of the research lies in providing the first longitudinal,

112 systematic practice-linked evidence to elucidate the direct outcomes of coaches'

113 learning experiences.

114 Methodology

115 Participants

116 Following institutional ethics approval, eight youth soccer coaches (M age = 27.0, SD

$117=3.4$, seven male and one female) were purposively sampled to take part (Patton, 
2002). Each participant was undertaking coaching practice at least twice a week, and alongside this, five coaches were completing the same month-long sport National Governing Body (NGB) coach education programme. The three further participants not attending formal coach education acted as a non-education group, matched in terms of coaching experience, age and operating domain. Each participant was qualified to United Kingdom Coaching Certificate (UKCC) Level Two or above, with a mean of 7.9 years' experience $(S D=2.6)$. Participants worked with male and female athletes of ages ranging from nine to 18 . Information about the participants is shown in Table 1.

[Table 1 near here]

\section{Study Design}

This research adopted a pragmatic quasi-experimental design, based on CPD evaluation models (Coldwell \& Simkins, 2011). The two groups of participants underwent multiple sessions of quantitative and qualitative data collection in baseline and follow-up phases. Immediately after the baseline phase, the 'education group' completed the NGB formal coach education course, comprising two weekends' contact time one month apart. Each weekend involved a mix of classroom-based delivery; group work; 'showcase' coaching; and simulated coaching practice with educator feedback. Course participants also completed a logbook of linked coaching sessions building towards an optional overall practical assessment. Participants were followed up six to nine months after the baseline data collection, allowing time for learning (Goodall et al., 2005). Participants were involved in data collection for a time period of one year. 
144 In order to link coaches' learning to their behaviours within training sessions, 145 systematic observation was adopted. In line with previous systematic observation 146 studies, each participant was filmed during at least two training sessions at each time

147 point (Table 1), generating 2505 minutes of footage in total (Cope et al., 2017).

148 Observed sessions were matched in terms of the context and player groups involved, 149 although session content and time of season at each time point were not controlled. 150 An adapted version of the Coach Analysis and Intervention System (CAIS; Cushion, 151 Harvey, Muir \& Nelson, 2012) was utilised, with six primary CAIS behaviours 152 identified as key behavioural markers for analysis as outlined in Table 2. Secondary 153 contextual-level detail (i.e. performance state, recipient, timing, content and type of 154 questioning) was coded for each primary behaviour, and the time spent in different 155 performance states was also collected and grouped into categories (Table 3). For 156 example, corrective feedback could have been given during a conditioned game (i.e. 157 playing performance state), while the athlete was completing the action (i.e. 158 concurrent timing), directed towards an individual (i.e. individual recipient), and 159 technical in nature (i.e. technical content) (Harvey, Cushion, Cope \& Muir, 2013). 160 These behaviours and practice state categories were adopted as directly aligning with 161 the education course learning outcomes, a strategy previously employed to measure 162 programme impact (Stodter \& Cushion, 2014). A trained coder coded the behavioural 163 and practice activity data for each category. A second trained coder carried out inter164 observer reliability, coding $10 \%$ of the data (van der Mars, 1989) and reaching $85.3 \%$ agreement $(\mathrm{SD}=3.4)$. Intra-observer agreement was $87.4 \%(\mathrm{SD}=4.8)$, meeting the level of $85 \%$ to provide acceptable reliability (van der Mars, 1989). 
[Table 2 near here]

168 [Table 3 near here]

169 Stimulated recall interviews

170 Qualitative data were collected using video-stimulated recall (SR) interviews to

171 enhance behavioural observation (Cope et al., 2017) by interpreting practice

172 behaviours, linking them to cognitive outcomes of changing knowledge. Where 'think

173 aloud' protocols, occurring during action, may be limited by coaches' self-awareness

174 and ability to verbalise thoughts during practice without task interference (Lyle, 2003;

175 Whitehead, Cropley, Huntley, Miles, Quayle \& Knowles, 2016), video SR interviews

176 invite participants to recall, aided by video clips of their behaviour, their cognitive

177 activity during that event (Lyle, 2003). SR interviews can also be tailored towards the

178 particular research question, in this instance using interview questions linking 179 participants' cognitions to their knowledge-in-use, reasoning, and learning. For 180 example, participants were first invited to identify occurrences or issues arising in their 181 coaching session that they considered relevant for discussion (Bernier, Cordon, 182 Thienot \& Fournier, 2011). They were then instructed to recall and describe the 183 thoughts they were personally experiencing during each of these occurrences, through 184 questions such as 'what did you notice as the session was happening?' and 'why did 185 you intervene at this point?' After participants had described the occurrence, the 186 researcher selected and played a corresponding video clip from pre-prepared footage 187 of the coach's practice. At this point, participants were asked if they had anything else 188 to add; a playback sequence designed to minimise additional layers of retrospective 189 reflection triggered by viewing the clips (Lyle, 2003). Each of the interview clip 190 sections was then extended with questions that linked cognitions to learning; such as 
191 'what knowledge did you use' and 'where did you learn to do this?' Therefore, 192 although session video clips and related questions were pre-prepared by the researcher, 193 the interviews followed a semi-structured format based on clips chosen by each 194 participant and the researcher together (Bernier et al., 2011). SR interviews took place 195 less than a week after each observed coaching session (Gilbert \& Trudel, 1999) and 196 lasted between 30 and 80 minutes (Table 1). Each typically covered six clips, 197 generating 1585 minutes of interview data overall. Research has demonstrated that 198 video can provide structure to reflective conversations and trigger behaviour change 199 in youth soccer coaches (Partington et al., 2015). As such, video SR interviews also 200 functioned as a 'guided reflection' intervention for all participants besides its use as a 201 data collection technique, enabling investigation of another informal learning source 202 (see section on 'Reflection').

203 Analysis

The systematic observation data were classified as rate per minute (RPM) behaviours, calculated by dividing the frequency of each behaviour by the total session time in minutes, and percentage of total session time spent in different performance states. Data were averaged for each key marker or practice state category (Tables 4, 5 and 6) across baseline and follow-up phases of data collection, to enable assessment of change in behavioural outcomes between time-points. The sixth primary behaviour,

210 general negative reinforcement occurred too infrequently to be included. The data set

211 consisted of discrete count data with small mean values close to zero, and practice

212 structure percentage data that violated the statistical assumption of independence, 213 which holds that one data point should not influence another (Field, 2013). Combined 214 with a mixed design and small sample size, inferential statistics were therefore deemed 215 inappropriate for these data (Ford, Yates \& Williams 2010). Descriptive statistics were 
used for percentage duration of practice states alongside primary and secondary CAIS

217 behaviour detail (i.e. recipient, timing, content and question type).

Interview data were analysed moving from basic description towards

219 increasingly abstract levels, using a constant comparative approach (Strauss \& Corbin,

220 1998). Concepts relating to knowledge were produced by labelling raw data extracts

221 then grouping them with others sharing common characteristics and creating new

222 concepts when extracts did not fit (cf. Groom, Cushion \& Nelson, 2011). Interview

223 data from the baseline phase were first analysed together, creating a matrix of

224 knowledge concepts that the coaches used 'pre-intervention'. Follow-up data were

225 then similarly coded and compared with baseline concepts in a process that involved

226 creating linkages, subcategories and categories connected to theoretical ideas.

227 Constant comparison was used to analyse changes in knowledge between the two time

228 points; concepts were deemed to have changed when they were qualitatively different

229 or mentioned more often (Saldaña, 2003). Analytical memos, peer review with a

230 'critical friend' and member checking of theoretical ideas were employed to enhance

231 rigour (Morse, 2016).

\section{Results and Discussion}

233 Analysis highlighted six main knowledge concepts that changed over the intervention

234 period, with participant groups demonstrating differing changes in knowledge use.

235 Systematic observation data, however, indicated that coaches' practice remained

236 relatively constant. Mean Rates Per Minute (RPM) of five of the primary behaviours,

237 alongside the secondary 'individual recipient' detail, are shown in Table 4. Each is

238 discussed with respect to the related qualitative themes. ${ }^{1}$

\footnotetext{
${ }^{1}$ Interview data are labelled by participant code and ' $F$ ' for those conducted in the follow-up phase.
} 


\section{Technical and Tactical Focus}

241 The coach education intervention impacted coaches' use of tactical knowledge. Those 242 who took part in the course initially reported using more technical than tactical 243 knowledge in their practice, illustrated by coach E4:

This pattern was reversed on follow-up, with the same coach providing an example of his more tactically-focused thinking during practice:

Coaches in the education group referred to the concept of tactical knowledge more often after attending the formal education course. They explained that this knowledge had come from a variety of sources, predominantly "experience of playing and coaching" (E4), but also "something that was mentioned on the [course]" (E3). E3

259 from" the course and the build-up of prerequisite courses. Non-education group coaches, who were seen to overall use tactics less than the education group in their 
N2 stating she was "still trying to keep the technical detail, that's not changed really". Asked about their tactical knowledge, these coaches also pointed to "watching other teams, training sessions, other coaches or games on TV...I guess that's where it comes from" (N1), without the additional focus of the formal coach education course. Taken together, this evidence suggests that the education experience may have influenced a change in coaches' use of pre-existing knowledge rather than altering the nature of their knowledge in this area. Coaches, consistent with other studies (e.g. Kearney, Carson \& Collins, 2018; Lara-Bercial \& Mallett, 2016), were seen to draw upon a combination of several interacting knowledge sources including playing experience, other coaches, watching sport and formal education.

Significantly, changes in reported knowledge use were reflected in patterns of coaching behaviour, specifically when looking at coaches' use of questioning. Secondary-level behaviour data (Table 5) showed that the proportion of technicallybased questions used by education group coaches changed differently across the intervention period to the non-education group. There was a drop in proportion of technical questions asked by education group coaches over time, coupled with an increased percentage of questions about technique by non-education group coaches. This suggests an important outcome of learning, seemingly linked to education, which impacted on both knowledge and questioning behaviours.

[Table 5 near here]

\section{Challenges and Questioning}

Questioning as a coaching intervention strategy linked to setting 'challenges' for players was a central theme of the coach education course. Participants demonstrated an altered understanding of these concepts after attending. Initial 'lip service' was paid 
286 to implementing challenges, while in reality delivering disguised directions; "the

287 challenge for you is can you score from checking out and then checking in?" (E1) (cf.

288 Cope, Partington, Cushion \& Harvey, 2016). On follow-up, coaches had adapted their

289 language to match an appreciation that they were attempting to allow players to make

290 decisions on when to perform skills, beginning to form links with the concept of 291 questioning:

"Well it's a question isn't it? It's the way you word it because you know the challenge is can we try to...it adds an element of choice to them that, rather than telling them what they should be doing, there are ways, they're achieving something" (E2,F).

Knowledge of the particular language and ways of using "supporting questions to try and draw that point out" $(\mathrm{E} 1, \mathrm{~F})$ was identified by coaches as an outcome of formal 298 learning, as "had I not been on the [course], maybe I wouldn't have had the 299 knowledge" (E2,F). In contrast, coaches who did not attend the course were seen to continue to question rhetorically without clear distinction in understanding. N1 exemplified this on consideration of his coaching intervention "that was the main challenge initially, but it sort of became a condition", while questioning was used in a disconnected and rationalistic manner, "to check understanding" (N2,F).

Despite these reported changes in knowledge, there was no observable transfer to coaches' behaviour in terms of use of questions. Mean values of questioning RPM for both groups of coaches, in Table 4 reflect a lack of change over time. Education group coaches may have encountered a ceiling effect, given high rates $(M=1.27)$ in comparison to research with equivalent coaches $(\mathrm{M}=0.69$ per minute; Cushion $\&$ Partington, 2011), raising the issue of question content. Secondary-level coaching 
behaviour data (Table 5) revealed a high ratio of convergent to divergent questions

311 across all coaches. Convergent questions, with a limited number of responses,

312 constrain athletes to a 'correct' answer, while effective divergent questioning requires

313 the learner to think through problems (Cope, et al., 2016). There were no noteworthy

314 changes in question type used by the coaches. Non-education group coaches used a

315 higher proportion of convergent questions than education group coaches overall, a

316 percentage split repeated post-intervention (Figure 3). This supports existing research

317 (Cope et al., 2016) in that coaches not undertaking education adopted the general

318 strategy of questioning, without fully understanding the type of questions asked and

319 underpinning philosophy - in contrast to those on the course who developed linkages

320 between knowledge concepts in this area.

\section{$321 \quad$ Practice structure}

322 Knowledge concepts relating to practice structure were also seen to change subtly over 323 time. Some coaches already knew about 'whole-part-whole' design "from courses and 324 also, I suppose college and PE" (E3). Latterly, the education group showed more 325 detailed understanding of the concept, for instance in addressing areas for 326 improvement through the initial 'whole' practice:

In the first game it's more about the build-up and are we getting into positions to shoot, which I think we did to a certain extent. If we hadn't done that then the part might have been slightly different. $(\mathrm{E} 3, \mathrm{~F})$

330 These coaches attributed continued use of the whole-part-whole format directly to the 331 formal education course, whereas non-education group coaches used the same practice 332 structure without the equivalent level of detail around how and why. Coach N1, for 333 example, reported implementing it second-hand because "it was the centre director's 
355 he explained, "when I get big [group] numbers like that it would be a case of getting

direction". As a result, the structure was described in a straightforward manner, with the 'part' seen as an opportunity to provide players with repetition of technique for transfer into a game; implicit behaviourist assumptions that belie the approach's intentions (Swanson \& Law, 1993):

Yeah we did a sort of whole-part-whole approach, broke the session down, played a big game, broke away into our teams, did some finishing, and then played the game again. $(\mathrm{N} 1, \mathrm{~F})$

Generally, participants showed evidence of interpretation in terms of an underlying behaviourist theory-in-use (Argyris, 1987). Practices were designed to "build up through warm-ups" (E5,F), starting unopposed and gradually adding in more interference, informed by ingrained wider knowledge or assumptions:

"probably because a mixture of that's the way I've done things as a player, that's the way I also do things with adults when I coach on a Saturday. The way I've been taught as well to build things up slowly and progressively" $(\mathrm{E} 3, \mathrm{~F})$

The quantitative data demonstrates a lack of change in practice activities (Table 6) which suggests an absence of meaningful learning whereby biography is 'transformed' to accommodate new knowledge (Moon, 2001). The individual data reveals that coaches E3 and E5 did not use any small-sided or full-sided game practices pre- and post-intervention respectively; reflected in high standard deviations. Moreover, N3 spent $61 \%$ (S.D. $=9.9)$ of post-intervention practice time in playing-type activities as them playing games". Practice state data was therefore heavily influenced by 
357 individual and contextual factors, with limited evidence of impactful learning, similar 358 to previous findings (Leduc, Culver \& Wethner, 2012).

$359 \quad$ [Table 6 near here]

\section{Learning Principles}

361 After attending formal education, there was greater mention of giving players

362 "situations to react to and see what works for them" $(\mathrm{E} 1, \mathrm{~F})$ in a more constructivist363 informed approach. However, coaches would still intervene to correct mistakes or 364 highlight positive outcomes "so they can think about what they've just done and attach 365 it to a positive reinforcement" (E2,F). This reveals a behaviourist-informed 366 interpretation of the espoused learning theory, creating a 'naïve-constructivist' 367 approach (Cushion, 2013). Mean RPM values (Table 4) were consistent over the 368 intervention period, reflecting pervasive accepted practices. RPMs of the five primary 369 CAIS behaviours did not substantially alter between baseline and follow-up, 370 suggesting coaches' reliance on 'trademark' behavioural profiles that were relatively 371 resistant to change over time. The concept of constructivist-informed learning 372 principles was therefore assimilated into coaches' existing repertoires on the basis of 373 assumed similarity to their existing practice, without cognitive changes (Leduc et al., 374 2012).

$375 \quad$ Players

376 Coaches' use of interpersonal knowledge relating to players appeared to alter, with 377 participants in the education group reporting using concepts of individuals' learning, 378 abilities and personalities to a greater extent. Coach E1 exemplifies his use of these 379 three concepts in combination: 
I know Josh now and he needs to be challenged and this didn't really challenge enough in this set up so he just kind of strolled through it. But then when it comes to the game he brings that mentality with him a bit... No he's a good player, he should do it... Some of them will try to do it because they're into that learning and they've got the idea that they're going to learn something by trying it. But Josh doesn't seem to have that. $(\mathrm{E} 1, \mathrm{~F})$

Following on from this, systematic observation data were examined for behaviours directed towards individuals (see table 4). Mean values showed a trend whereby on average, coaches increased their rate of coaching behaviours directed towards individuals after attending formal education, with behaviours in the non-education group showing no change. Data indicated that this was mainly due to large changes in individually-directed behaviours by coaches E1 and E4, who displayed increases of $77 \%$ and $98 \%$ respectively. With a high baseline RPM of 2.18 , coach E4 acknowledged that 'speaking to individuals is kind of what we've done a lot of anyway before the course', yet this behaviour had almost doubled in frequency on follow-up, apparently linked to setting and exploring individual challenges; 'just from experience that since I've started doing that in the sessions, it's been kind of effective' (E4,F). By comparison, E2 increased RPM behaviours towards individual recipients by $11 \%$ and E5 by 17\%, while E3 showed a 15\% decrease. These findings are valuable in suggesting learning bridging the knowledge-practice gap, in particular when reinforcing previous practices. Coaches appeared to develop a greater focus on individuals "from the [course], that I've learnt to maybe think about the players in a group more, rather than just actually what the session is" (E2,F).

\section{Reflection}


404 Finally, coaches not taking part in formal education demonstrated changes in their use 405 of intrapersonal knowledge concepts, relying on "a little reflection in action, and 406 reflection on action afterwards" (N1) "to generate new knowledge" (N3). Coach N2 407 explained,

I'm starting to think a bit more...to get to know the players, to get to know what I'm dealing with...I've started to look for different things from when I did the first lot [of interviews]. (N2,F)

The data suggests this enhanced use of reflection was linked to taking part in the SR interview protocol. It is unclear why only the non-education group reported changing use of reflective practice however. Interview data aligned with evidence that individuals' pre-existing knowledge, coupled with coaching contexts, influenced this learning. For example, coach N3 described how "I'm always kind of reflecting”, as "one thing I did learn at university was the value of the reflection cycle". As a result, he was able to engage in reflective conversations facilitated by club context, informing practice: "that [behaviour] was just a gradual thing that we developed through the club and just as coaches talking and discussing and reflecting really". It may be that SR interviews provided a particular contextual impetus and a framework for coaches not taking part in formal education to develop reflection (Gilbert \& Trudel, 2001).

\section{Study Limitations}

Although the sample size employed was larger than in previous studies, descriptive statistics were most appropriate for analysing groups of coach behaviours, limiting widely generalisable conclusions. Indeed, the complex and situation-specific nature of coaching is a confounding factor that impacted on the level of variability in behaviour. 
427 While maintaining a naturalistic approach is important, future research could aim to

428 recruit larger groups of coaches working within the same context, account for factors

429 such as session content and timing within athletic seasons, and observe more coaching

430 sessions over longer time periods (Cope et al., 2017), enabling inferential statistics to

431 add weight to the claims made.

\section{Conclusion}

433 The results of this study demonstrate that learning had an impact on coaches'

434 knowledge and practice behaviours. Completion of a formal education course

435 influenced changes in the use of knowledge around tactics and engaging with 436 individual players, reflected in an altered proportion of technical to tactically-related

437 questions and a trend towards increased behaviours directed at individuals.

438 Participants also showed evidence of changes in knowledge of practice structure,

439 challenges and questioning, learning principles and reflection, although behaviours

440 and practice activities generally remained consistent in these areas. The minimal 441 impact of learning on observed coaching behaviour, alongside interview data, revealed 442 some disconnect between knowledge and situated action, suggesting a lack of deep 443 learning (Moon, 2004) around the theoretical underpinnings of certain practices.

444 Coaches were able to adopt and reinforce knowledge without challenging deeply held 445 assumptions, reflecting common criticisms of coach education as a relatively 'low 446 impact' endeavour for generating meaningful change. 'Traditional', 'deep seated' 447 practices can be resistant to change, and changing behaviour is particularly 448 challenging using short, formal coach education courses. While some impact was 449 evidenced here, the findings pose questions to the duration and follow-up of 450 educational episodes. It was apparent that coaches not taking part in formal education 
451 developed across a narrower range of concepts over the same period. While learning 452 was linked to a variety of interacting sources including coaching and playing 453 experiences, the evidence suggests formal education did have added 'learning impact' 454 for those taking part.

455 456

457 458

459 460

The results highlight the importance of exploiting mixed methods to enable longitudinal monitoring of coaches' thinking and behaviours and examine how cognitive changes are reflected in contextualised practice. Unlike the prevalent selfreport perceptions of learning, a more integrated approach can illuminate the unseen reasoning behind coaches' behaviours and provide an index of change. This research is the first to provide direct evidence of the impact of learning experiences in multiple coaches over time. Learning from education was demonstrated to interact with previous knowledge and individual and contextual factors (e.g. Stodter \& Cushion, 2017). Therefore research that takes a view of coaches' wider learning as an integrated whole is needed to better understand coaches' development.

5

(1)


477 Argyris, C. (1987) Reasoning, action strategies, and defensive routines: The case of organisational change and development. Vol 1 p89-128. Greenwich: JAI

Cushion, C.J. (2013). Applying Game Centred Approaches in coaching: a critical 
Review, 2(1), 61-76.

499

500

501

502

503
Cushion, C.J., Ford, P.R., \& Williams, A.M. (2012a). Coach behaviours and practice structures in youth soccer: Implications for talent development. Journal of Sports Sciences, 30(15), 1631-1641

Cushion, C.J., Harvey, S., Muir, B., \& Nelson, L. (2012b). Developing the Coach Analysis and Intervention System (CAIS): Establishing validity and reliability of a computerised systematic observation instrument. Journal of Sports Sciences, 30(2), 203-218

Deek, D., Werthner, P., Paquette, K.J., \& Culver, D. (2013). Impact of a large-scale coach education program from a lifelong-learning perspective. Journal of Coaching Education, 6(1), 23-42.

DeMarco, G.M., Mancini, V.H., \& Wuest, D.A. (1997). Reflections on change: a qualitative and quantitative analysis of a baseball coach's behaviour. Journal of Sport Behavior, 20(2), 135-163.

Dieffenbach, K. (2008). Exploring learning among USA cycling licensed Coaches. Journal of Coaching Education, 1(2), 1-19

Eraut, M. (1994). Developing professional knowledge and competence. Lewes: Falmer Press.

Eraut, M. (2000). Non-formal learning and tacit knowledge in professional work. British Journal of Educational Psychology, 70, 113-136.

Field, A. (2013). Discovering Statistics Using IBM SPSS Statistics (4 ${ }^{\text {th }}$ Edition). 
London: Sage.

520

Ford, P.R., Yates, I., \& Williams, A.M. (2010). An analysis of practice activities and instructional behaviours used by youth soccer coaches during practice: Exploring the link between science and application. Journal of Sports Sciences, 28(5), 483-495.

Gallo, G.J., \& De Marco, G.M. (2008). Self-assessment and modification of a Division I strength and conditioning coach's instructional behavior. Journal of Strength and Conditioning Research, 22(4), 1228-1235.

Gilbert, W. \& Côté, J. (2013). Defining coaching effectiveness: a focus on coaches' knowledge. In: P. Potrac, W. Gilbert \& J. Denison (Eds.), Routledge Handbook of Sports Coaching, (pp.147-159). Abingdon: Routledge.

Gilbert, W., \& Trudel, P. (1999). An evaluation strategy for coach education programs. Journal of Sport Behavior, 22, 234-250.

Gilbert, W., \& Trudel, P. (2001). Learning to coach through experience: Reflection in model youth sport coaches. Journal of Teaching in Physical Education, 21, 1634.

Griffiths, M., Armour, K., \& Cushion, C. (2016). 'Trying to get our message across': Successes and challenges in an evidence-based professional development programme for sport coaches. Sport, Education and Society. DOI: $10.1080 / 13573322.2016 .1182014$

Groom, R., Cushion, C., \& Nelson, L. (2011). The delivery of video-based performance analysis by England youth soccer coaches: towards a grounded 
542 Goodall, J., Day, C., Lindsay, G., Muijs, D., \& Harris, A. (2005). Evaluating the Impact of CPD (Research Report No. 659). London: Department for Education

Harvey, S., Cushion, C.J., Cope, E., \& Muir, B., (2013). A season long investigation into coaching behaviours as a function of practice state: the case of three collegiate coaches. Sports Coaching Review, 2(1), 13-32.

International Council for Coaching Excellence (2016). ICCE's Standards for Higher and Skills.

Lara-Bercial, S., and Mallett, C.J., (2016). The practices and developmental pathways

Lyle, J. (2003). Stimulated recall: a report on its use in naturalistic research. British Education Bachelor Coaching Degree Programmes - Consultation Draft (International Coaching Degree Standards). Retrieved July 12 2016, from http://www.icce.ws/_assets/files/icds-draft-2-final-08-07-16.pdf

Kearney, P.E., Carson, H.J., \& Collins, D. (2018). Implementing technical refinement in high-level athletics: exploring the knowledge schemas of coaches. Journal of Sports Sciences, 36(10), 1118-1126. DOI: 10.1080/02640414.2017.1358339.

Leduc, M., Culver, D.M., and Werthner, P., (2012). Following a coach education programme: coaches' perceptions and reported actions. Sports Coaching Review, 1(2), 135-150.

Educational Research Journal, 29(6), 861-878. DOI: 
Lyle, J. (2007). A review of the research evidence for the impact of coach education. International Journal of Coaching Science, 1, 17-34.

Millar, S., Oldham, A.R.H., Donovan, M. (2011). Coaches's self-awareness of timing, nature and intent of verbal instructions to athletes. International Journal of Sports Science \& Coaching, 6(4), 503-513.

Moon, J. (2001).Short courses \& modules: improving the impact of learning, training \& professional development. London: Kogan Page.

Moon, J. (2004). A handbook of reflective and experiential learning - theory and practice. London: RoutledgeFalmer.

573 Morse, J.M. (2015). Critical analysis of strategies for determining rigor in qualitative inquiry. Qualitative Health Research, 25(9), 1212-1222.

575 Nelson, L., Cushion, C.J., \& Potrac, P. (2006). Formal, nonformal and informal coach learning: a holistic conceptualisation. International Journal of Sports Science \& Coaching, 1(3), 247-259.

578 Nelson, L., Cushion, C., \& Potrac, P. (2012). Enhancing the provision of coach education: the recommendations of UK coaching practitioners. Physical Education and Sport Pedagogy, DOI:10.1080/17408989.2011.649725.

581 Partington, M., and Cushion, C.J., (2013). An investigation of the practice activities and coaching behaviours of professional top-level youth soccer coaches. Scandinavian Journal of Medicine and Science in Sports, 23(3), 373-382. 
Partington, M., Cushion, C.J., Cope, E., and Harvey, S. (2015). The impact of video feedback on professional youth football coaches' reflection and practice behaviour: a longitudinal investigation of behaviour change. Reflective Practice: International and Multidisciplinary Perspectives, DOI: 10.1080/14623943.2015.1071707.

Patton, M.Q. (2002). Qualitative research and evaluation methods. Thousand Oaks, CA: Sage.

Saldaña, J. (2003). Longitudinal qualitative research: analysing change through time. Oxford: Altamira Press.

Schempp, P.G., \& McCullick, B. (2010). Coaches' Expertise. In: J. Lyle \& C. Cushion (Eds.) Sports Coaching: Professionalisation and Practice (pp.221-231). China: Elsevier.

Søvik, M.L., Tjomsland, H.E., Larsen, T., Samdal, O., \& Wold, B., (2017). Barriers in implementing coach education in grassroots youth football in Norway. International Sport Coaching Journal, 4(2), 162-176.

Stodter, A., and Cushion, C.J., (2014). Coaches' learning and education: a case study of contexts in conflict. Sports Coaching Review, 3(1), 63-79.

Stodter, A., and Cushion, C.J., (2017). What works in coach learning, how, and for whom? A grounded process of soccer coaches' professional learning, 9(3), 321338.

Stoszkowski, J., \& Collins, D. (2015). Sources, topics and use of knowledge by coaches. Journal of Sports Sciences, DOI: 10.1080/02640414.2015.1072279. 
606 Strauss, A., \& Corbin, J. (1998). Basics of qualitative research: Techniques and 607 procedure for developing grounded theory (2nd ed.). Thousand Oaks, CA.

608

609

610 611

612

613

614

615

616

617

618

619

620

621

622

623

624

625

626

627

628

629

630

631

0

Swanson, R. A., \& Law, B. (1993). Whole-part-whole learning model. Performance Improvement Quarterly, 6(1), p43-53

Trudel, P., Gilbert, W., \& Werthner, P. (2010). Coach education effectiveness. In: Lyle, J. \& Cushion, C.J. (Eds.), Sports coaching: Professionalisation and practice (pp. 135-152). China: Elsevier.

van der Mars, H. (1989). Observer reliability: issues and procedures. In P.W. Darst, D.B. Zakrajsek, V.H. Mancini, (eds.), Analysing Physical Education and Sport Instruction (pp. 53-80). Human Kinetics: Champaign.

Whitehead, A.E., Cropley, B., Huntley, T., Miles, A., Quayle, L., \& Knowles, Z. (2016). 'Think aloud': Toward a framework to facilitate reflective practice amongst rugby league coaches. International Sport Coaching Journal, 3(3), 269-286. 
Table 1. Participants, design and data collection for each participant group. Key: $\mathrm{E}=$ Education group, $\mathrm{N}=$ non-education group, $\mathrm{SR}=\mathrm{Stimulated}$ Recall

\begin{tabular}{|c|c|c|c|c|c|c|c|c|c|c|c|}
\hline \multirow{2}{*}{$\begin{array}{l}\text { Participant } \\
\text { number }\end{array}$} & \multirow[t]{2}{*}{ Coaching Context } & \multirow[t]{2}{*}{ Age } & \multirow{2}{*}{$\begin{array}{l}\text { Years } \\
\text { Coaching }\end{array}$} & \multicolumn{4}{|c|}{ Baseline Data Collection } & \multicolumn{4}{|c|}{ Follow-up Data Collection } \\
\hline & & & & $\begin{array}{l}\text { Observation } \\
\text { M Minutes } \\
\end{array}$ & S.D. & $\begin{array}{l}\text { SR Interview } \\
\text { M Minutes } \\
\end{array}$ & S.D. & $\begin{array}{l}\text { Observation } \\
\text { M Minutes } \\
\end{array}$ & S.D. & $\begin{array}{l}\text { SR Interview } \\
\text { M Minutes } \\
\end{array}$ & S.D. \\
\hline E1 & $\begin{array}{l}\text { Centre of Excellence / } \\
\text { Further Education College }\end{array}$ & 27.9 & 10.8 & 162.4 & 11.5 & 99.8 & 69.9 & 135.4 & 46.1 & 89.6 & 44.5 \\
\hline $\mathrm{E} 2$ & Academy & 26.9 & 5.5 & & & & & & & & \\
\hline E3 & Centre of Excellence & 35.3 & 9.8 & & & & & & & & \\
\hline $\mathrm{E} 4$ & Centre of Excellence & 24.0 & 7.0 & & & & & & & & \\
\hline E5 & Centre of Excellence & 26.5 & 3.8 & & & & & & & & \\
\hline N1 & $\begin{array}{l}\text { Girls' Player } \\
\text { Development Centre / } \\
\text { Further Education College }\end{array}$ & 23.7 & 8.0 & 172 & 11.3 & 110.3 & 41.3 & 166.7 & 18.9 & 102.3 & 34.9 \\
\hline N2 & Community & 27.1 & 12.0 & & & & & & & & \\
\hline N3 & Academy & 24.8 & 6.0 & & & & & & & & \\
\hline
\end{tabular}


Table 2. Primary behavioural observation classifications and descriptions in the CAIS coding process (Adapted from Cushion et al., 2012)

\section{Behavioural Classification Behavioural Description}

\begin{tabular}{ll}
\hline Specific Feedback (positive) & $\begin{array}{r}\text { Specific positive verbal statements that specifically aim to } \\
\text { provide information about the quality of performance, e.g. } \\
\text { 'that was good defending' } \\
\text { Specific Feedback (negative) }\end{array}$ \\
$\begin{array}{r}\text { Specific Feedback (negative) Specific negative verbal } \\
\text { statements that specifically aim to provide information } \\
\text { about the quality of performance e.g. 'don't force the pass' } \\
\text { General positive verbal statements or non-verbal gestures, e.g. } \\
\text { 'good' }\end{array}$ \\
General Feedback (negative) \\
$\begin{array}{r}\text { General negative verbal statements or non-verbal gestures, e.g. } \\
\text { 'don't do that again' }\end{array}$ \\
Question \\
$\begin{array}{c}\text { Statements that contain information that specifically aim to } \\
\text { improve the player(s) performance at the next skill attempt } \\
\text { e.g. 'pass it earlier next time' } \\
\text { Coach asks a question }\end{array}$ \\
\hline
\end{tabular}

Table 3. Categories of practice states, adapted from the CAIS (Cushion et al., 2012).

\begin{tabular}{lll}
\hline $\begin{array}{l}\text { Practice State } \\
\text { Category }\end{array}$ & $\begin{array}{l}\text { Performance } \\
\text { State } \\
\text { Classification }\end{array}$ & Definition \\
\hline Game state & $\begin{array}{l}\text { Small sided game } \\
\text { Full sided game }\end{array}$ & $\begin{array}{l}\text { Two goals, realistic to regulation rules, both teams } \\
\text { scoring in the same way }\end{array}$ \\
Playing state & $\begin{array}{l}\text { Phase of play } \\
\text { Possession game } \\
\text { Conditioned game }\end{array}$ & $\begin{array}{l}\text { Attack vs. defence play which differs from a game } \\
\text { state in adaptations to rules, e.g. only one team } \\
\text { scores, variations in goals, scoring or area of play }\end{array}$ \\
& $\begin{array}{l}\text { Physiological } \\
\text { Technical practice } \\
\text { Practice/Training state }\end{array}$ & $\begin{array}{l}\text { Warm-up or cool down } \\
\text { Individual/group activity covering isolated technical } \\
\text { skills or game incidents and patterns; unopposed or } \\
\text { opposed }\end{array}$ \\
& $\begin{array}{l}\text { Functional practice } \\
\text { Other }\end{array}$ & $\begin{array}{l}\text { Coach is managing/addressing players to explain } \\
\text { practices or transition to new practice state; breaks }\end{array}$ \\
State & & \\
\hline
\end{tabular}


Table 4. Table showing mean values for Rate Per Minute of coaching behaviours at baseline and follow-up for education and non-education groups.

\begin{tabular}{|c|c|c|c|c|c|}
\hline \multirow{2}{*}{$\begin{array}{l}\text { Behaviour } \\
\text { (Mean Rate Per Minute) }\end{array}$} & \multirow{2}{*}{$\begin{array}{l}\text { Participant } \\
\text { Group }\end{array}$} & \multicolumn{2}{|c|}{ Baseline } & \multicolumn{2}{|c|}{ Follow up } \\
\hline & & $\mathbf{M}$ & S.D. & $\mathbf{M}$ & S.D. \\
\hline \multirow[t]{3}{*}{ Questioning } & Education & 1.27 & 0.59 & 1.28 & 0.40 \\
\hline & Non-Education & 0.65 & 0.18 & 0.93 & 0.16 \\
\hline & Total & 1.04 & 0.56 & 1.15 & 0.36 \\
\hline \multirow[t]{3}{*}{ General Reinforcement (+) } & Education & 0.92 & 0.48 & 1.05 & 0.63 \\
\hline & Non-Education & 1.18 & 0.48 & 0.89 & 0.28 \\
\hline & Total & 1.02 & 0.47 & 0.99 & 0.51 \\
\hline \multirow[t]{3}{*}{ Specific Reinforcement (+) } & Education & 0.39 & 0.07 & 0.53 & 0.16 \\
\hline & Non-Education & 0.42 & 0.09 & 0.55 & 0.20 \\
\hline & Total & 0.40 & 0.05 & 0.54 & 0.13 \\
\hline \multirow[t]{3}{*}{ Specific Reinforcement (-) } & Education & 0.10 & 0.11 & 0.18 & 0.18 \\
\hline & Non-Education & 0.24 & 0.33 & 0.44 & 0.62 \\
\hline & Total & 0.15 & 0.21 & 0.28 & 0.38 \\
\hline \multirow[t]{3}{*}{ Corrective Reinforcement } & Education & 0.26 & 0.18 & 0.44 & 0.30 \\
\hline & Non-Education & 0.20 & 0.14 & 0.18 & 0.14 \\
\hline & Total & 0.23 & 0.16 & 0.35 & 0.27 \\
\hline \multirow[t]{3}{*}{ Individual Recipient } & Education & 1.71 & 0.41 & 2.37 & 1.14 \\
\hline & Non-Education & 1.87 & 1.15 & 1.86 & 0.44 \\
\hline & Total & 1.77 & 0.69 & 2.18 & 0.93 \\
\hline
\end{tabular}


Table 5. Table showing mean values for percentage of secondary questioning behaviours at baseline and follow-up for education and non-education groups.

\begin{tabular}{llcccc} 
& & \multicolumn{2}{c}{ Baseline } & \multicolumn{2}{c}{ Follow up } \\
\cline { 2 - 6 } Behaviour (\%) & Participant & M & S.D. & M & S.D. \\
\hline Technical Question (\%) & Education & 25.46 & 10.20 & 10.31 & 8.03 \\
& Non-Education & 14.57 & 5.17 & 24.39 & 4.27 \\
& Total & 21.37 & 9.93 & 15.58 & 9.75 \\
Tactical Question (\%) & Education & 54.73 & 10.19 & 62.46 & 21.83 \\
& Non-Education & 32.74 & 12.16 & 21.31 & 13.88 \\
& Total & 46.49 & 15.20 & 47.03 & 27.95 \\
Divergent Question (\%) & Education & 19.87 & 5.33 & 20.33 & 6.64 \\
& Non-Education & 13.03 & 7.51 & 10.41 & 0.32 \\
& Total & 17.30 & 6.70 & 16.61 & 7.18 \\
Convergent Question (\%) & Education & 80.00 & 5.37 & 79.39 & 6.06 \\
& Non-Education & 86.38 & 8.49 & 88.78 & 0.83 \\
& Total & 82.39 & 6.93 & 82.91 & 6.69 \\
\hline
\end{tabular}

Table 6. Table showing mean values for percentage time spent in different practice states at baseline and follow-up for education and non-education groups.

\begin{tabular}{llcccc} 
& Participant & \multicolumn{2}{c}{ Baseline } & \multicolumn{2}{c}{ Follow up } \\
Practice State (\% Time) & Group & M & S.D. & M & S.D. \\
\hline Game & Education & 18.08 & 15.28 & 15.96 & 14.00 \\
& Non-Education & 21.20 & 7.84 & 21.47 & 3.10 \\
& Total & 19.25 & 12.39 & 18.03 & 11.09 \\
Playing & Education & 25.80 & 6.77 & 24.60 & 11.84 \\
& Non-Education & 22.60 & 8.73 & 32.13 & 15.29 \\
Training & Total & 24.20 & 5.52 & 28.37 & 9.67 \\
& Education & 34.34 & 7.79 & 38.12 & 10.40 \\
Other & Non-Education & 32.10 & 10.05 & 20.60 & 13.42 \\
& Total & 33.22 & 6.38 & 29.36 & 8.49 \\
& Education & 21.75 & 2.97 & 20.69 & 2.09 \\
& Non-Education & 24.13 & 3.83 & 25.95 & 2.69 \\
& Total & 22.94 & 2.43 & 23.32 & 1.70 \\
\hline
\end{tabular}

